\title{
La escultura pública en el municipio vizcaíno de Leioa
}

\section{Public Sculpture in the Biscay Town of Leioa}

\author{
IÑIGO SARRIUGARTE-GÓMEZ \\ Facultad de Letras. Universidad del País Vasco. \\ inigo.sarriugarte@ehu.es
}

Recibido: 2 de julio de 2013

Aprobado: 23 de febrero de 2014

\begin{abstract}
Resumen
Estudio pormenorizado relacionado con la escultura pública en el municipio vizcaíno de Leioa, donde se recogen alrededor de unas 30 esculturas, que componen el paisaje plástico de este municipio y que han sido catalogadas y analizadas en base a una metodología histórico-artística. Se ha incorporado en este proceso de inventariado todo aquel elemento plástico, que de alguna manera pueda representar el carácter socio-cultural y la historia en todas sus ramificaciones del municipio de Leioa. Desde la política municipal, se han llevado a cabo dos premisas fundamentales; por una parte, embellecer los espacios urbanos y, por otra, recordar la memoria de los personajes que destacaron por su actividad social, intelectual o cultural en este pueblo. Dentro del ámbito de la investigación realizada en torno al patrimonio de la escultura pública en este municipio, hemos articulado los siguientes grupos temáticos: 1-Propuestas relacionadas con el contexto histórico-cultural del municipio. 2-Obra de escultores vascos de posguerra. 3-Propuestas vinculadas con la Universidad del País Vasco. 4-Obra relacionada con el Palacio Artaza. 5-Obra varía.
\end{abstract}

Palabras clave: Vizcaya, Leioa, escultura pública, arte contemporáneo.

Sarriugarte-Gómez, I. (2014): La escultura pública en el municipio vizcaíno de Leioa. Arte, Individuo y Sociedad, 26(3) 419-436

\begin{abstract}
Detailed study related with the public sculpture in the Biscay town of Leioa, where there are some 30 public sculptures, making up the plastic landscape of this county. These public sculptures have been cataloged and analyzed, using an art historical methodology. In this process of inventory, we have incorporated all plastic elements that can somehow represent the social-cultural character and history of Leioa. From local politics, they have developed two fundamental premises; on the one hand, beautify urban spaces and, second, recall the memory of the celebrities that have stood out for their social, intellectual or cultural activity in this town. Within the field of the research about heritage of public sculpture in this county, we have articulated the following thematic groups: 1-Proposals related to historical and cultural context of the municipality. 2-Sculptures of the postwar Basque sculptors. 3-Proposals related to the University of the Basque Country. 4-Works related to Artaza Palace. 5-Other works. Keywords: Biscay, Leioa, public sculpture, contemporary art.
\end{abstract}

Sarriugarte-Gómez, I. (2014): Public Sculpture in the Biscay Town of Leioa. Arte, Individuo y Sociedad, 26(3) 419-436 
Sumario: 1. Introducción al concepto de escultura pública. 2. La escultura pública en el municipio de Leioa. 3. Grupos temáticos, 4. Conclusiones. Referencias.

Este artículo recoge resultados de la investigación Escultura pública en Leioa. Un patrimonio que define a un municipio financiada por el Ayuntamiento de Leioa (Bizkaia).

\section{Introducción al concepto de escultura pública}

La escultura pública es uno de los principales valores de concepción urbana, de hecho, las propuestas conmemorativas representan una buena parte de los hitos del medio urbano, convirtiéndose en reflejo de su evolución económica y social, así como cultural. Al estar situados en una plaza, ante un edificio público o en un lugar visible, se vuelven una parte indisoluble de ciertos puntos paisajísticos, a la vez que se fundamentan como ejes focales de un medio urbano, lo que contribuye a formar la imagen de una población o un lugar singularizado (Lozano, 1989: 10). Estos lugares permiten elaborar diferentes lecturas, que incluyen una carga política y social, en relación al momento en que se hicieron, así como por la historia de su colocación y de su devenir.

La evolución de la reciente escultura pública ha sido un largo proceso de democratización, que ha reflejado cambios de actitudes hacia el reino de lo público. Sin embargo, la escultura pública no se debería formalizar únicamente desde el parámetro de la autorreferencialidad, sino que se tendría que articular en base a diferentes condicionantes externos y a las propias particularidades de cada territorio urbano, en donde se ubican las obras. Para la materialización de numerosas propuestas, el discurso personal del artista queda en cierta manera condicionado por el propio espacio, es decir, en relación a su emplazamiento físico. A menudo, lo que suele ocurrir es que el artista es invitado posteriormente, una vez que se ha diseñado y construido todo el entramado urbano, convirtiéndose de este modo en un mero decorador del espacio, siendo su única función la de adaptarse al medio existente, cuando realmente tendría que haber intervenido desde un principio, siendo esta misma una de las características que hemos encontrado en la conformación de la escultura pública del municipio vizcaíno de Leioa.

Numerosos especialistas, entre ellos especialmente Harriet F. Senie (1992: 16-17) han hablado sobre la distancia surgida entre los lenguajes empleados y el conocimiento estético del viandante, especialmente en referencia al discurso abstracto, el cual llega a resultar incomprensible para gran parte de los ciudadanos. Evidentemente, este hecho se explica por la falta de unos planes educativos y pedagógicos apropiados que acerque el arte contemporáneo al público en general. Cuando hablamos de escultura pública, no nos podemos limitar únicamente a una serie de condicionantes, como distribución financiera, ubicación urbana y selección del artista, sino que igualmente debemos asumir cuales van a ser los mecanismos para informar y educar al urbanita sobre la escultura pública que va a ser emplazada.

En general, la aparición de la escultura pública en los espacios urbanos responde a los diferentes programas de rehabilitación urbana con el propósito de regenerar espacios de esparcimiento, de humanizar y socializar la estructura urbana. La 
disposición de una escultura puede fomentar la recuperación de un barrio antiguo, favorecer los cambios de imagen de la ciudad, contribuir a su ordenamiento, a la vez que acerca el arte contemporáneo a la ciudadanía, siendo estos aspectos características que se encuentran en el conjunto patrimonial escultórico de Leioa

Todo lugar que acoge esculturas puede implicar una mayor imagen de recuperación espacial y urbana, posibilitando el descubrimiento del lugar, así como su inevitable humanización dentro de un ámbito social. Por ejemplo, Aldo Rossi ve inseparable el fenómeno urbano con la creación artística. La visión de la ciudad no sólo se compone de los hitos arquitectónicos, sino obviamente de una serie de elementos físicos, que se sustentan en ocasiones en las esculturas públicas, ya que a modo de "signos de la voluntad colectiva expresados a través de los principios de la arquitectura, parecen colocarse como elementos primarios, como puntos fijos de la dinámica urbana." (Rossi, 1979: 52) Tal y como lo podemos observar en el ámbito local de Leioa en la pieza Una ola de hierro (1988-89) de Néstor Basterretxea.

En un intento de delimitar conceptos terminológicos, debemos anotar lo siguiente:

Las denominaciones Arte Público y Arte en espacios públicos aluden a prácticas artísticas diferentes. Arte en espacios públicos se refiere a la Escultura Pública Monumental que surge en los años 60 y que se caracteriza por el binomio arquitecto-escultor como fórmula magistral. Las premisas que suelen acompañar a este tipo de proyectos tienen que ver con la renovación de los espacios urbanos como reflejo de la cultura y el desarrollo económico. (Castañer, 2002: 10).

Por otra parte, Arte Público respondería a cualquier propuesta artística, desde graffiti a arte callejero (Street Art), que previamente ha sido diseñada para ser ubicada en un dominio público, habitualmente exterior y especialmente accesible para todos los ciudadanos. El arte público es el resultado de una colaboración entre el artista, el público y el cliente. En cualquier caso, ambos proyectos se basan en una intervención en el medio urbano, dejando una huella visible. De acuerdo a PaulArmand Gette,

El lugar ideal para el encuentro entre arte y el público seguramente no es el museo, que siempre selecciona a sus visitantes, sino un espacio exterior. Es muy ingenuo pensar que el museo está abierto para cualquiera y que el arte es de interés general. Uno debe hacer una elección: o el arte es elitista - por qué no - y busca refugio en galerías y museos o muestra su cara en las calles y parques, que todavía no lo hace popular. Me gusta esta posición incómoda del arte vis-à-vis con la sociedad, lo que ha creado organismos de la cultura sólo para aliviar su consciencia y mantener el control de un fenómeno impredecible. (Gette, 2004: 287).

Para el artista Siah Armajani, referente fundamental del arte público, la concreción terminológica del concepto de público se centraría en

Todo lo que pertenece al público. Todo lo que es desprivatizado y colocado en la realidad pública. El término público expresa la totalidad de la vida, el trabajo, los edificios, carreteras, tiendas, fábricas, oficinas y almacenes alrededor de donde se mueve y vive la gente. La relación entre arquitectura, arquitectura de landscape y escultura pública existe 
porque todos están en lugares públicos; al estar en lugares públicos se hace posible está relación. El arte público y la arquitectura tienen diferentes lenguajes, diferentes historias $y$ diferentes sensibilidades. Ninguno suplanta al otro. Ellos simplemente coexisten. (Armajani, 2004: 68).

Para definirse como "espacio público", se requiere que pueda ser empleado por los ciudadanos independientemente de quien sea el propietario. En cualquier caso, el concepto de espacio público se puede llegar a entender de diferentes maneras. En general, debemos encontrar un espacio abierto, así como vestíbulos abiertos al público, es decir, lugares que son de uso público, caso de los que se sitúan en una estación de ferrocarril o aeropuerto. También, se deben considerar aquellas esculturas que se encuentran en fachadas de edificios de propiedad o uso privado, siendo el edificio una propiedad de una comunidad de vecinos, de una iglesia o un banco, porque su visión resulta claramente pública. Ciertamente, el arte público pertenece a las ciudades y está hecho para las ciudades. Igualmente, para Javier Maderuelo (1994: 19), el objetivo del arte público "es satisfacer al conjunto de ciudadanos no especialistas en arte contemporáneo y cuya ubicación es el espacio abierto. Además, la obra de arte público debe conferir al contexto un significado estético, social, comunicativo y funcional."

\section{La escultura pública en el municipio de Leioa}

El objetivo primordial de esta investigación fue materializar un estudio históricoartístico de carácter pormenorizado en torno a la escultura contemporánea colocada en lugares públicos en dicha localidad. Este municipio vizcaíno está vinculado al área metropolitana de Bilbao, siendo conocido por ubicar el principal campus de la Universidad del País Vasco. Se trata de un municipio claramente relacionado con la industrialización, que se comenzó a instalar a finales del siglo XIX. No obstante, el verdadero cambio demográfico y urbanístico se produce a partir de los años 60 , a pesar de que algunos enclaves todavía mantienen su fuerza más rural. La industria está muy diversificada en base al acero, química, mecánica, alimentaria y del vidrio

Los márgenes temporales del conjunto escultórico analizado en esta investigación se sitúan desde mediados del siglo XX hasta nuestros días, a excepción de algunas piezas, como las copias extraídas del palacio Artaza de principios de siglo o el pedestal para José María de Acha de 1930-31.

Este estudio ha ido más allá de la mera curiosidad identificativa, ya que ha pretendido abordar ante todo un análisis orientado hacia la comprensión de sus elementos formales, materiales, temáticos e históricos. Para ello, se han asumido unas premisas centradas en el habitual rigor científico y sistemático de un trabajo historiográfico.

Desde el primer momento, el material inventariado ha ido multiplicándose, ya que se han ido incorporando nuevas piezas, según el estudio avanzaba. Con el propósito de sistematizar todos los datos en el proceso de catalogación, se han formalizado una serie de fichas o modelos tipificados, donde se aportan ítems relacionados con el título, autor, material, fecha de ejecución y colocación, etc., siendo en general estas dataciones cercanas o similares. 
Como se puede comprobar en este estudio, los espacios relacionados con las vías rodadas resultan de gran valor estratégico, ya que son ubicaciones habituales para estas piezas, caso de la autovía Bilbao-Getxo y algunas de sus rotondas, donde por ejemplo se sitúa la monumental Bizkaia. Una ola de Hierro de Néstor Basterretxea.

En relación con la búsqueda de información y posterior realización de algunos de los textos, se ha contactado con los artistas y las empresas especializadas en la fundición artística del bronce y en grandes montajes metálicos, como Alfa Arte S.A. (Eibar) y Vilà (Valls, Tarragona). Incluso, se ha recabado información procedente de los fondos del archivo municipal de Leioa y especialmente de bibliotecas pertenecientes a distintos ámbitos, sobre todo las relacionadas con la Universidad del País Vasco y la Biblioteca Foral de Bizkaia. También, en algunos casos, se han realizado consultas a distintas personas relacionadas de una manera u otra con la pieza plástica en cuestión, sirva de ejemplo, los contactos con Carmen Cervera, nieta de Canuto Achútegui, propietario del palacio Atxutene o palacio Zabala y principal artífice de la colocación del único cruceiro existente en esta localidad.

Se ha querido incorporar en este proceso de inventariado todo aquel elemento plástico, que de alguna manera pueda representar el carácter socio-cultural y la historia en todas sus ramificaciones del municipio de Leioa. Por este motivo, la catalogación ha prescindido de cualquier cortapisa estética, ya que de lo contrario se hubieran tenido que dejar numerosos ejemplos fuera de este trabajo, quedando a nuestro parecer, el marco de interpretación histórico-artístico de esta localidad vizcaína claramente amputado y mutilado. Por esta razón, hemos decidido incluir piezas que van desde la placa conmemorativa y exenta en recuerdo de Manuel Tunón de Lara hasta el obelisco situado en el principal boulevard del municipio, acercándose este último elemento más al ámbito arquitectónico.

Bajo el espíritu de esta prioridad, se ha llegado a cerrar este inventariado aproximadamente con unos 30 referentes, lo que demuestra la existencia de un número muy sorprendente al tratarse de una localidad, que no se ha caracterizado históricamente por ser un punto neurálgico en el marco cultural de Bizkaia, como evidentemente lo puede ser Bilbao u otras localidades, que cuentan con mayor densidad demográfica, dimensión territorial y potencial económico. En este sentido, podemos extraer como primera conclusión en relación con el acervo plástico en la localidad de Leioa: la importancia que adquiere el patrimonio escultórico público en este municipio, una tendencia que posiblemente irá nutriéndose de nuevas incorporaciones en el futuro.

Muchas de las esculturas ubicadas en Leioa responden al planteamiento programático de Javier Maderuelo (2000: 51-68), al definirse como intervenciones más o menos técnicas, dentro de un micro urbanismo; caracterizadas por el propósito de acondicionar plazas y calles, junto al consiguiente proyecto y construcción de equipamiento urbano. En general, no se puede hablar de acciones artísticas, que se relacionen con intervenciones donde prime el aspecto estético frente al meramente constructivo, quedando relegada esta intencionalidad quizás a futuras propuestas. La realización de las obras se ha ido concibiendo una vez que el emplazamiento estaba ya realizado, ajustándose el escultor al entramado urbano.

Desde el gobierno municipal, se han planteado dos premisas fundamentales; por 
una parte, embellecer los espacios urbanos y, por otra, recordar la memoria de los personajes que destacaron por su actividad social, intelectual o cultural en este pueblo, destacando entre estos la placa a Manuel Tuñón de Lara y la escultura conmemorativa a la vecina del municipio Jesusa María Bilbao y Arizmendi, más conocida como Txutxa.

Resulta evidente que entre las principales intervenciones, que se realizan dentro de la escultura pública contemporánea, los monumentos e imágenes conmemorativas puedan ser para los vecinos las que mayor interés generan, ya que de una manera $\mathrm{u}$ otra sirven para la pervivencia de un recuerdo o una tradición, de ahí el pedestal de Jose María de Acha y El Manchonero de Lourdes Umerez, entre otras. Aunque el desarrollo de la escultura en el espacio urbano ha ido alterando su valor ideológico y estético, ciertamente seguimos encontrándonos con el valor conmemorativo y la memoria histórica de un hecho o una persona.

Los principales promotores de la escultura pública en Leioa han sido las instituciones públicas, convirtiéndose en los indiscutibles agentes que han financiado las obras, caso del Ayuntamiento de Leioa y la propia Diputación Foral de Bizkaia. Pero, también encontramos grandes empresas que han dejado su huella, sirva de ejemplo el grupo francés Vicrila S.A. con la escultura El Manchonero. Incluso, podemos observar la participación vecinal, especialmente mediante la Asociación de San Bartolome, en relación a la escultura conmemorativa a la vecina del municipio Txutxa. Otro caso digno de mencionar ha sido el interés que tuvo el arquitecto José María de Smith Solaun en la colocación de una serie de diez atlantes en uno de sus edificios proyectados, gracias a las facilidades que le brindó la promotora inmobiliaria.

Este municipio ha mantenido desde hace años un visible interés por el desarrollo de la escultura pública, lo que ha permitido dotar al espacio ciudadano de carácter y significación, mientras que el tiempo lo ha ido cargando simbólicamente y se ha convertido en lugar emblemático para sus vecinos, sirva de ejemplo, el obelisco de Leioa, como lugar habitual de encuentro para los leioaztarras. Harriet F. Senie (1992:

5) plantea que los vecinos de toda condición necesitan un sentido de identidad y de lugar y el arte suele servir y acomodarse a estas necesidades. En este sentido, la reciente historia de la escultura pública ha mostrado que el arte público fomenta la conciencia de una comunidad en su responsabilidad con las circunstancias locales y ayuda a entender las necesidades prácticas y estéticas del público.

Los emplazamientos de las esculturas se encuentran diseminados por todos los barrios, aunque la mayoría se encuentran en el centro, caso de las piezas de Rob Krier, Jorge Oteiza, Néstor Basterretxea y Vicente Larrea, entre otros. Las últimas en colocarse han ido asumiendo un marco más periférico, caso del Bosque de la Vida, quedando ubicado al lado del embalse Lertutxe y en el mismo arboretum del Campus de la universidad.

También, debemos notificar la cuestión de la perdida o traslado territorial de algunas obras, siendo este último caso lo ocurrido con el busto de José María de Acha, actualmente instalado en el campo de futbol Gobela del Arenas Club de Getxo, lo que significa que únicamente ha quedado en Leioa el pedestal con sus bajorrelieves. La pérdida más elocuente se ha producido con la Sagrada Familia de Ramón Vargas Leguizamón, realizada con poliéster y colocada en 1976 en Viviendas 
de Vizcaya, en la Calle Iparaguirre, $\mathrm{n}^{\circ}$ 20, así como la imagen de tamaño reducido de San Canuto, mártir de Dinamarca, realizada por Vicente Larrea (abuelo del actual escultor del mismo nombre y apellido), que estuvo situada en una hornacina exterior de una de las entradas del palacio Atxutene. Por otra parte, la copia de la Artemisa de Gabii de Praxíteles, que en un principio estuvo instalada en el palacio Artaza, acabó severamente mutilada y destruida a mediados de los años ochenta.

\section{Grupos temáticos}

Dentro del ámbito de la investigación realizada en torno al patrimonio de la escultura pública en este municipio, encontramos los siguientes grupos temáticos: 1-Propuestas relacionadas con el contexto histórico-cultural del municipio. 2-Obra de escultores vascos de posguerra. 3-Propuestas vinculadas con la Universidad del País Vasco. 4-Obra relacionada con el Palacio Artaza. 5-Obra varía.

El primer grupo sería uno de los más numerosos y se encuentran aquellas propuestas que de una manera u otra están vinculadas con el contexto histórico, cultural y social del municipio de Leioa. Entre estas destacamos aquellas esculturas que se sitúan junto a alguna sede emblemática. Por ejemplo, la pieza Hostoa (Fig. 1), de Juanjo Novella, que simula una hoja de parra en acero al carbono, se ubica al lado del palacio Mendibile, uno de los primeros caseríos en Bizkaia de finales del XVII y donde se encuentra la actual sede del Consejo Regulador de la denominación de origen del Bizkaiko Txakolina. La pieza viene articulada por un juego de trepanaciones, que permiten proyectar sombras en el suelo a través de los diversos huecos existentes, produciendo un interesante efecto visual sobre los viandantes que pasan por la zona.

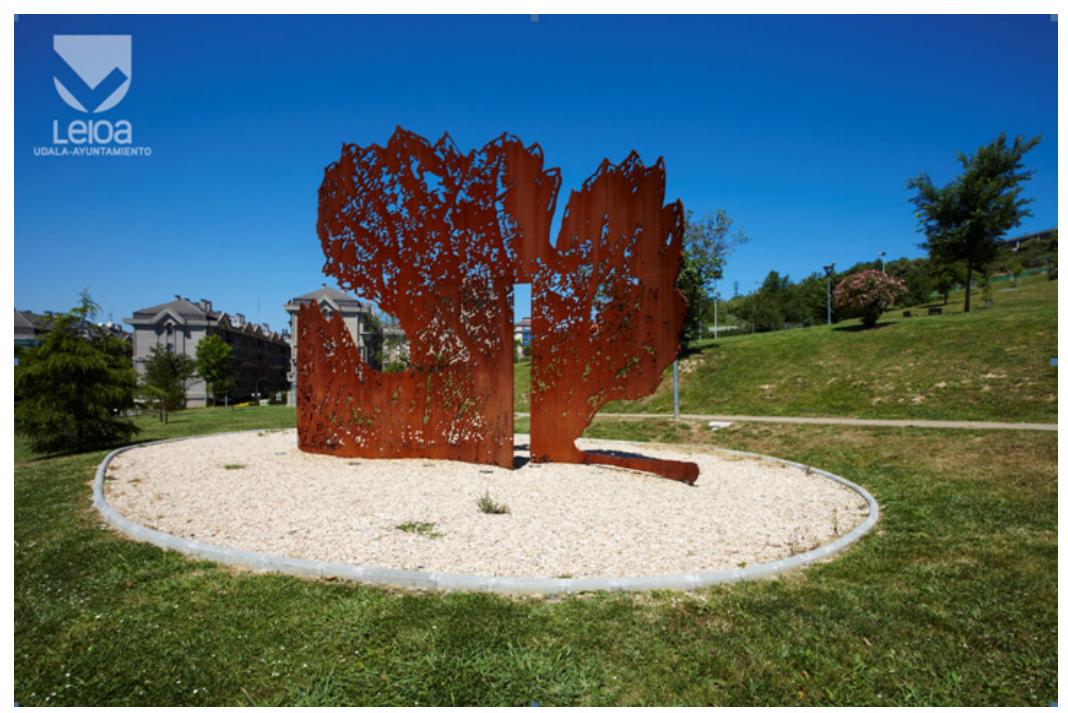

Figura 1. Juanjo Novella. Hostoa, 2008-2009. Procedencia: Ayuntamiento de Leioa. 
De igual manera, Esférica (Fig. 2) de Jesús Lizaso se ubica junto a otro edificio histórico como es la Torre Altxaga o también conocida como Ondizdorrea, recientemente rehabilitada. Se trata de una casa-torre de principios del siglo XVI, donde se encuentra la sede del deporte rural vasco de Leioa. La escultura seleccionada recoge la idea representativa de un harrijasotzaile con sus desarrollos volumétricos, exagerados, abultados y de carácter notablemente miguelangelescos.

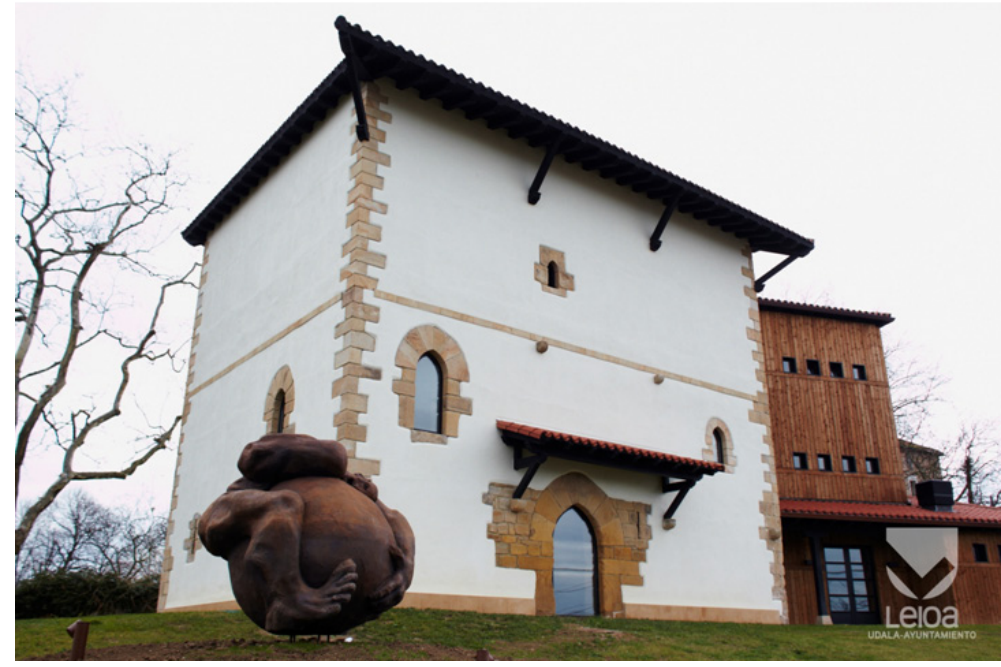

Figura 2. Jesús Lizaso. Esférica, 2012. Procedencia: Ayuntamiento de Leioa.

La pieza Esférica, que comienza a plantearse en el año 2000, entra dentro de la serie denominada Bustin Arima, donde como bien anota Esteban Sánchez (2007: 22): "Lizaso parte condicionado por el oficio, desde un punto de vista ceramista, desde la visión básica de un oficial de la rama del metal. Y trata de dominar la técnica amparándose en una figura humana -bastante gruesa, con rasgos etnográficos-." Se observa la figura del harrijasotzaile en el momento de la alzada con la piedra levantada y apoyada sobre sus rodillas.

Para conmemorar el arraigo histórico del barrio de Lamiako, se ubica Lamia de José Ramón Gómez Nazabal, en la estación del metro de Lamiako respondiendo al contexto etimológico del nombre de este barrio leioaztarra, donde desde $1978 \mathrm{se}$ celebra la famosa Maskarada, que alude a la representación festiva de la historia mitológica vasca, donde entre sus protagonistas principales se encuentran las lamias. Este barrio no es el único que cuenta con un nombre toponímico relacionado con dichos genios, ya que también se encuentra en otros lugares de nuestra geografía vasca, como Lamiategi (Oñati), Laminazilo (Isturitz) y Lamiaran (Mundaka), entre otros. (Barandiaran, 2006: 142) Con objeto de unir la fiesta de la Maskarada y el recuerdo a las antiguas divinidades vascas, Gómez Nazabal fundió en la misma pieza la forma de una lamia con máscara, asumiendo algunos de los habituales parámetros formales, que suelen conllevar a este tipo de seres mitológicos. De hecho, su imagen más popular se observa cuando aparece peinando sus largas cabelleras o cuando se 
recoge el pelo, tal y como ha sido anotado en los diferentes relatos recopilados por José Miguel Barandiarán y Julio Caro Baroja, entre otros.

Por otro lado, respecto a este mismo barrio, debemos recordar que antiguamente era una zona de marismas, con la consiguiente creencia popular de que estaba poblada por numerosas lamias, que curiosamente el escritor Antonio Trueba recogería en El canto de la Lamia.

La escultura Txutxa (2002) de Miguel Ángel Antolín Lería surge por iniciativa de la Asociación de San Bartolomé como homenaje a "Txutxa", seudónimo de Jesusa María Bilbao y Arizmendi (1910-2001), vecina del barrio de Tellería. No sólo fue una vecina modelo, sino que destacó por ejercer una constante ayuda a sus prójimos, además de encargarse de las diferentes tareas de la comunidad parroquial. De hecho, su primer objetivo fue convertirse en misionera, como lo fue su hermana Irene, religiosa franciscana, cuya labor desempeñó en la República del Congo.

Resulta muy significativo el San Juan Bautista (1960) de Jesús Torre Goiricelaya, labrada en piedra, donde se reproduce con exactitud la figura, que se encuentra en el interior de la iglesia, con una altura de $1,58 \mathrm{~cm}$. Aunque no hay ningún dato feaciente, es posible que dicha imagen tallada en madera haya sido ejecutada alrededor de 1900, en base a un canon estilístico neo-barroco. Ambas esculturas se sitúan en la Iglesia de San Juan Bautista, enfatizando tanto desde su interior como desde su exterior la devoción hacia este profeta, cuyo culto está muy arraigado en los pueblos de Euskadi, siendo igualmente motivo de fiestas patronales, en Hernani, Andoain, Agurain y obviamente en Leioa.

El Soplador de la Fábrica de Vidrios de Lamiako (2002) de Lourdes Umerez se presenta como un homenaje a la dilatada trayectoria de la empresa conocida como $L a$ Vidriera Vizcaína, siendo una de las primeras de este tipo en España. Esta compañía comienza su andadura el 13 de septiembre de 1890, gracias a la iniciativa de Amadeo Deprit, hijo de padres belgas que se trasladaron a Bilbao para dedicarse al negocio vidriero (López, 2001: 100). La pieza muestra la técnica del vidrio soplado, es decir, una técnica de fabricación de objetos de vidrio a través de la creación de burbujas en el vidrio fundido. .

También, debemos destacar el Pedestal realizado para situar el busto de José María Acha (1930-31) de Manuel Basterra, que está claramente relacionada con el Arenas Club, cuyos primeros partidos comenzaron a disputarse en Lamiako hasta la temporada 1914-15, para después comenzar a jugar en el campo del Real Club Jolaseta, en Neguri. Más adelante, al inicio de la temporada 1925-26, se terminarían las obras del nuevo campo de futbol de Ibaiondo (Leioa), en los terrenos propiedad de este equipo, donde se sitúa actualmente el Grupo Ibaiondo, por este motivo, encontramos en este barrio un pedestal, que en su inicio contaba con el busto original en bronce de José María de Acha (18??-1928) y que actualmente se encuentra en el campo de fútbol del Gobela, estadio habitual del Arenas Club. Se ha querido respetar el pedestal por su carácter escultórico, ya que cuenta con relieves biográficos y alusivos al homenajeado. El conjunto fue inaugurado en 1931, siendo realizado por el escultor vizcaíno Manuel Basterra (1892-1947).

Por último destacar el Txistulari (2003) de Jesús Torre Goiricelaya, que no sólo hace alusión conmemorativa a la figura del txistulari, sino también al atabalero, figura 
relevante a la hora de amenizar cualquier evento que se celebraba en Leioa, como en otros tantos municipios de la geografia vasca. La pieza se caracteriza por una libertad de ejecución que le permite recrear un tratamiento sin una exahustiva concreción tipológica, simplemente, se deja llevar para resaltar únicamente aquellos elementos que más le interesan.

Dentro del segundo grupo se encuentran propuestas que están vinculadas a nombres de sólido reconocimiento artístico, dentro de los escultores vascos de posguerra, así como a algunos de sus más destacados discípulos.

Entre las más emblemáticas, encontramos Proposición dinámica (Fig. 3) de Jorge Oteiza, surgida de la investigación realizada por dicho autor en su famoso Laboratorio de Tizas, que desde principios de los años setenta en adelante se irán convirtiendo en verdaderos prototipos para esculturas públicas.

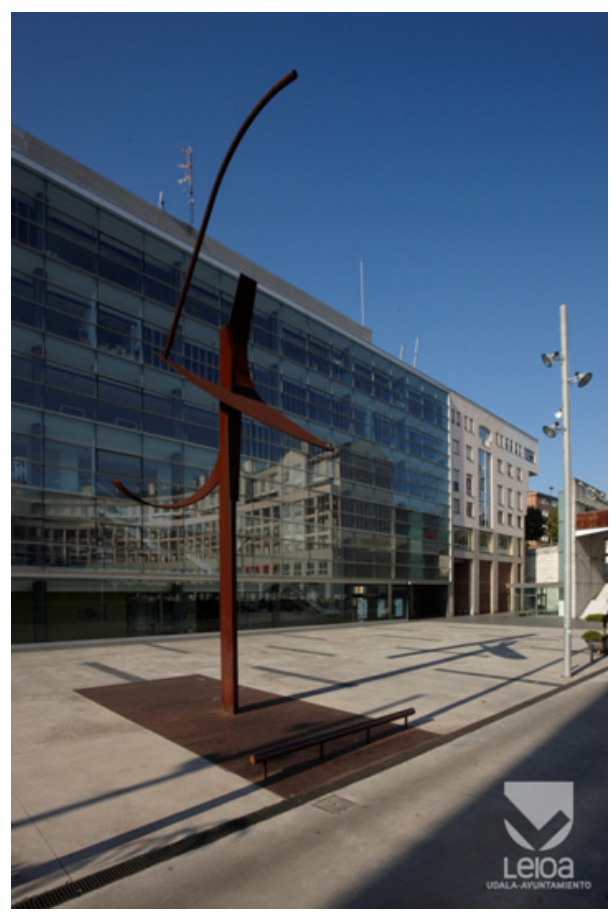

Figura 3. Jorge Oteiza. Proposición dinámica, 2002. Procedencia: Ayuntamiento de Leioa.

Este laboratorio de tizas es un conjunto de modelos realizados en miniatura, donde el artista fue aplicando todos sus lenguajes plásticos, siendo en cierta manera la culminación de una trayectoria de constante investigación. Las piezas serían materializadas no sólo en tiza, sino también en madera y hojalata. Esta ha sido una de las fuentes más fructíferas que las instituciones han buscado para disponer de alguna de las obras de este escultor internacional en los ámbitos públicos, de ahí que se llevará una concienzuda campaña por ir trasladando dichos modelos de taller a esculturas en formato monumental. Esta derivación constructiva se fue acrecentando durante las últimas décadas de vida del escultor, tal y como ocurre con Proposición dinámica, 
situada en la plaza Rekalde, frente al edificio del Kultur Etxea, en lo que sería un juego comparativo de intereses visuales entre una fachada totalmente acristalada de corte racionalista y el juego dinámico y orgánico del acero corten que se emplea para resucitar dicho modelo experimental. En este sentido, fue el propio artista el que decidió el enclave y la disposición para la escultura, observando el interesante abanico de relaciones visuales y formales que se producía entre el entorno y su obra.

Otro de los principales representantes de los escultores vascos de posguerra es Néstor Basterretxea con dos piezas. La primera se titula Una ola de hierro (Fig. 4), donde se presta a un interesante juego interpretativo a modo de alegoría en torno al esfuerzo voluntarioso de los vizcaínos ante las vicisitudes de los tiempos y como este pueblo ha ido demostrando que el desarrollo económico ha sido algo sine qua non al sentir del territorio foral. El empleo del acero implica manifiestas correlaciones con la personalidad y la historia industrial de Bizkaia, marcada por la metalurgia y la industria naval, sectores que en tiempos pasados resultaron claves para el crecimiento económico de la provincia.

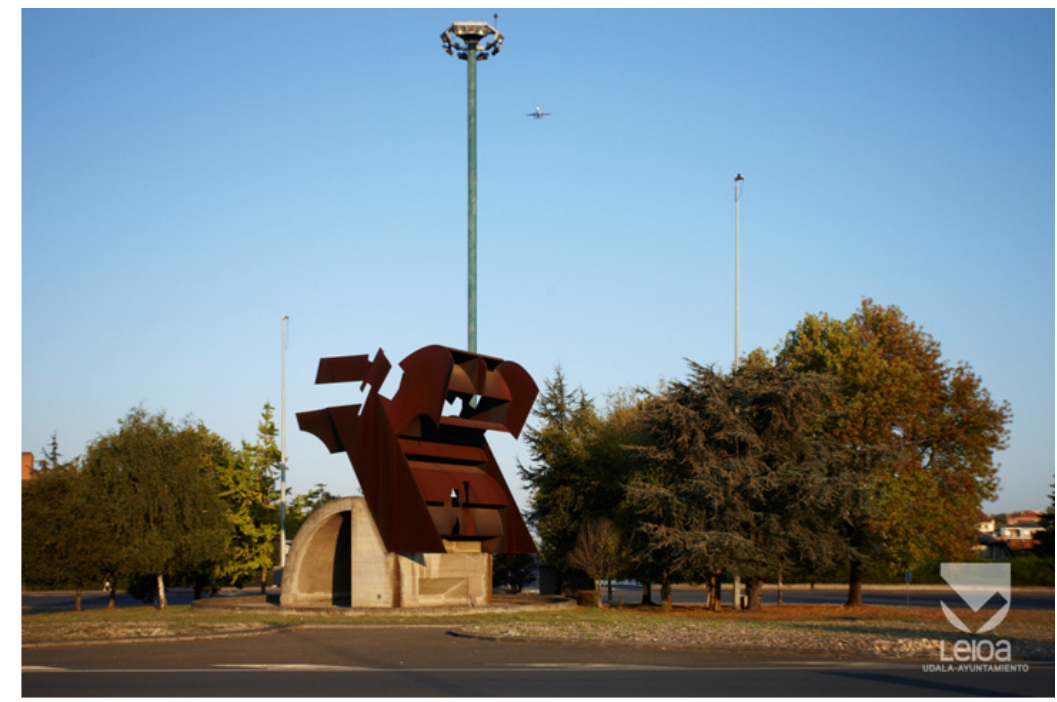

Figura 4.Néstor Basterretxea. Una ola de Hierro, 1988-89. Procedencia: Ayuntamiento de Leioa.

Resulta atrayente la parte inferior, realizada en hormigón con una forma semicircular, aludiendo a la forma de un puente, como elemento articulador y comunicativo entre materiales y formas divergentes, así como entre distintas maneras de percibir y apreciar la vida, tal y como se fue forjando este territorio, compuesto por sectores tan dispares como alejados en sus objetivos, pero que les unía el sentido de aportar lo mejor para Bizkaia. La obra, que está circunscrita por una estructura a modo de estanque, enfatizando su relación con el agua, permite una comparativa formal con el movimiento de las propias olas, es decir, con estas ondas mecánicas y perturbaciones de la superficie acuosa, que se sitúan en el límite entre la atmósfera y el océano, al igual que la pieza intermedia entre la atmósfera y la tierra. 
La otra pieza del mismo escultor titulada Leioako indarra (2001) se relaciona con el trabajo de las estelas que realiza a partir de 1973, años donde los estudios sobre los ritos y los mitos funerarios y mortuorios en el País Vasco estaban muy desarrollados y totalmente asentados. En cualquier caso, estas investigaciones habían empezado a adquirir un notable peso desde los años cincuenta en adelante. De acuerdo a Joseba Zulaika (2003: 5), la antropología que se hacía en el País Vasco al comienzo de los años sesenta, había sido una disciplina fundacional a falta de otros discursos. En esta línea, no se puede olvidar el trabajo realizado por antropólogos como Miguel de Barandiarán y Caro Baroja.

Como ha afirmado el mismo Jorge Oteiza en varias ocasiones, Remigio Mendiburu ha sido uno de los principales impulsores del denominado renacimiento cultural vasco, perteneciendo en 1966 al grupo Gaur. Su participación dentro de este colectivo fue un impulso para difundir en la sociedad vasca las posibilidades creativas del arte contemporáneo, pero sin olvidar el origen identitario de estos escultores. Entre su amplio elenco productivo, dos obras especialmente han quedado en la memoria de todos, estamos hablando del testigo de la Korrika y la escultura del Premio Manuel Lekuona que entrega Eusko Ikaskuntza.

Sin título (2009) de Remigio Mendiburu se presenta como uno de los principales prototipos plásticos del artista, donde aparecen sus constantes formales y especialmente el interés por la conjunción volumétrica de los elementos componentes. Este mismo planteamiento se lleva a cabo en diversas piezas en madera, donde diferentes secciones se entrecruzan e intercalan direcciones dispares, caso de Puño Mazo de 1966 en su versión menos barroca, para llegar al paroxismo con Zugar de 1969 o Raíces de 1971.

La producción de Vicente Larrea se moldea a partir de mediados de los años setenta, con una producción artística entre esculturas de formato medio y gran tamaño, todas ellas fundidas en bronce y en general con un destino público, sirva de ejemplo la Broca de 1975-76, situada provisionalmente en el palacio de AjuriaEnea, en Vitoria-Gasteiz y posteriormente trasladada al Museo de Bellas Artes de esta localidad. Actualmente, se encuentra frente al Centro-Museo Vasco de Arte Contemporáneo-Artium.

En Retablo de la libertad (1989-90), observamos un maremágnum de convulsiones orgánicas, que se desplazan constantemente. Parece que la materia es impelida a conquistar uno de sus estados naturales: la estaticidad. Es como si la escultura estuviera compuesta de una materia líquida, que ha sido congelada súbitamente. Por otro lado, la escultura se relaciona con cuestiones histórico-políticas, tal y como se puede observar en otras piezas de bronce del autor como Proceso de Burgos de 1970, el relieve Fuga de 1970, o toda la seria de Gartzela, que comienza a realizarse a finales de los años sesenta. Las alusiones reivindicativas de la pieza se conexionan con una situación política, que venía marcada por su atributo de negación de libertad y expresión. Ahora, con este relieve, ubicado en el boulevard de Leioa, nuevamente se asume un grito de libertad, pero como escape y huída ante una situación política enfrascada en su propia incapacidad para buscar una resolución, de ahí que la pieza se emplace con desarrollos laberínticos, que representan el propio entramado sin salida al que se ha visto la misma sociedad vasca y su endogámico problema político. 
Por último dentro de este grupo no podemos olvidarnos de Besarkada I (2005) del navarro José Ramón Anda, artista que tomará como referencia plástica a los escultores vascos de posguerra. Besarkada I guarda semejanza formal en su parte superior con algunos de estos prototipos de muebles-escultura, tal y como ocurre con Aita-amaren aulkiak de 1991, donde además de la forma alargada y rematada en arco de medio punto, a modo de respaldo se añaden sendos bancos, que favorecen su proyección utilitaria. Besarkada I, realizada en bronce patinado, pretende fusionar simbólicamente a todos los leioaztarras, indiferentemente de su origen o procedencia, de su consideración ideológica o religiosa. Se plantea mediante este trabajo una oportunidad para ver más allá de los habituales confinamientos culturales, de asumir que existe una diferencia, que puede enriquecer el pedestal autóctono.

Dentro del grupo de esculturas conexionadas con la Universidad del País Vasco, debemos destacar El bosque de la vida (2001-2003) de Zade + Vilá Associats (Fig. 5), situada dentro del parque botánico, conocido como Arboretum de Leioa, diseñado por el estudio vallisoletano de arquitectura Land Art Studio 2002, en la ladera sursudeste del campus universitario vizcaíno. En esta superficie compuesta de unos 1700 árboles, encontramos una pequeña arboleda, que quizás sea el elemento más llamativo y emblemático de todo su conjunto: el Bosque de la Vida, un columbario inaugurado en el año 2003, que homenajea a todos aquellos que han donado su cuerpo para la ciencia, exactamente para el estudio de la Medicina. Este columbario se gesta a partir de la iniciativa de Francisco Doñate, catedrático de Anatomía Humana, en el Departamento de Neurociencias (Facultad de Medicina y Odontología de la UPV/ EHU) que durante más de 26 años estuvo guardando en su despacho las cenizas de estos donantes, llegando a tener alrededor de cien urnas. Ante esta situación, solicitó incansablemente a los diferentes rectores que fueron pasando por la universidad, la creación de un panteón-urnario, viéndose finalmente su esfuerzo recompensado con la materialización de este proyecto.

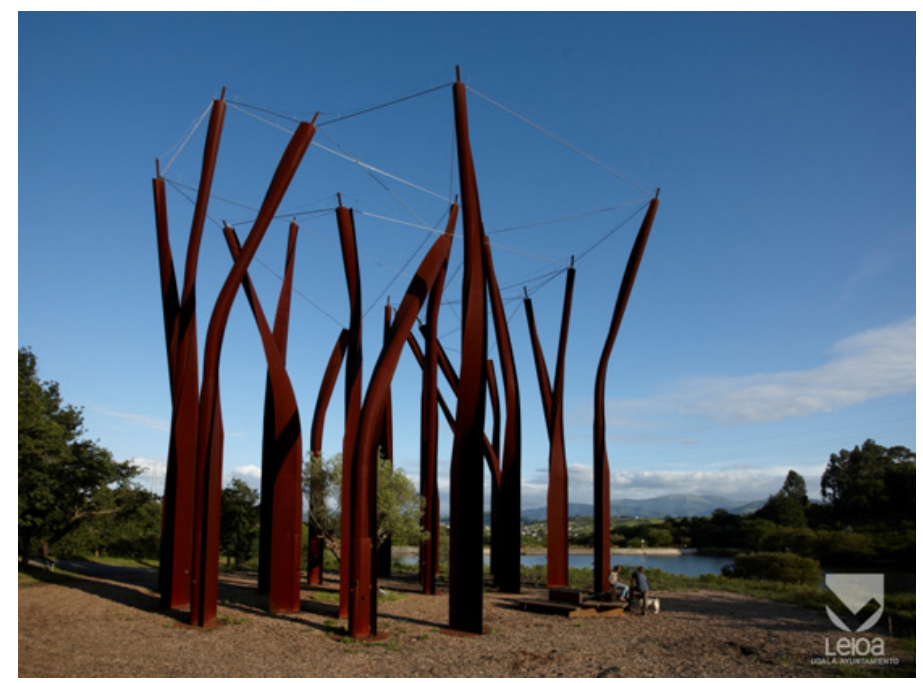

Figura 5. Zade + Vilá Associats. El bosque de la vida, 2001-2003.

Procedencia: Ayuntamiento de Leioa. 
Esta propuesta a modo de receptáculo para las cenizas de dichos donantes, ha convertido a la UPV/EHU en la primera universidad estatal y en una de las únicas del mundo que dispone de este recinto para cenizas. La idea de los autores fue recrear un lugar, y no tanto un objeto o escultura, fomentando un espacio que representará la vida en si misma y para ello eligieron el diseño de un bosque, con todos los componentes simbólicos que representan. Su propuesta ha ido más allá del simple hecho de generar un panteón, parque o cementerio, ya que han querido jugar con un elemento representativo de la vida, como es un bosque, pero que a su vez sirva como lugar depositario de cenizas. Se trata de un espacio abierto, sin elementos que impiden la entrada, facilitando un flujo y movimiento constante a través de él, tal y como debe ser la ciencia, sin elementos restrictivos, en constante evolución y desarrollo dinámico.

La pieza Sin título (cuerno) (1995) fue realizada por un grupo de alumnos de quinto curso dentro de la especialidad de Escultura, Pintura y Grabado, en la licenciatura de Bellas Artes, durante el curso 1994-1995, siendo ubicado dicho trabajo en junio de ese último año. Inicialmente, tomaron parte unos 14 estudiantes, sin embargo, este dilatado grupo se fue reduciendo a un número menor, entre los que se encontraban Félix Barcina, Jorge López, Mercedes Hoyuelos, Isidoro Fernández de la Fuente, Eva Bolado y José Carrera. Finalmente, con el devenir del tiempo será Félix Barcina quien asumirá todo el peso de la ejecución final de la pieza. Aunque en la actualidad esta escultura ha sido trasladada varios metros de su ubicación original, sigue siendo una parte imprescindible del paisaje exterior de la Facultad de Bellas Artes de la UPV/EHU.

Por último, fuera del campus, pero directamente relacionada con este centro educativo, encontramos la Placa conmemorativa a Manuel Tuñón de Lara de (2000), uno de los principales historiadores españoles. Este intelectual no sólo se ha caracterizado por la producción de un numeroso elenco literario publicado, sino por el reconocimiento magisterio, que ha recibido por parte de otros colegas de su campo profesional, quienes le han destacado como uno de los principales expertos en la historiagrafía española del tardo-franquismo y la democracia Su estilo literario ha estado marcado por la agilidad narrativa, cercana al estilo periodístico y en base a una gran capacidad interpretativa, que siempre estaba apoyada por un sólido soporte bibliográfico y heremerográfico, aunque no tanto archivístico, debido a su condición de exiliado desafecto al régimen franquista. Después de su dilatado exilio en Francia, regresa definitivamente a su país natal en el verano de 1981, residiendo en primer lugar en Donostia, y posteriormente en Leioa, muy cerca del propio campus. La relación con la UPV/EHU se produce a partir de 1982, cuando por entonces su rector Gregorio Monreal le propone incorporarse a dicha institución, siendo ya catedrático recién jubilado en la Universidad de Pau.

Otro de los grupos temáticos abordados en esta investigación son aquellas esculturas relacionadas con el Palacio Artaza, edificio ubicado en un amplio solar irregular de casi 300.000 metros cuadrados, localizado en el Arenal de Artaza, siendo este lugar el que da nombre a la casa. Se realiza en 1914 por el arquitecto Manuel María de Smith Ibarra (1879-1956) como encargo para el empresario Víctor Chávarri, Marqués de Triano. Este arquitecto, que ha sido el principal introductor del 
estilo inglés en el País Vasco, diseñó numerosos edificios en conexión con la moda reinante en los círculos de los emergentes burgueses vascos, durante finales del siglo XIX y principios del XX. Posteriormente, en 1979, el palacio fue abandonado por la Marquesa de Triano, permaneciendo a partir de entonces vacío, se pensó darle uso como residencia oficial del Lehendakari del Gobierno Vasco, pero con el traslado de la capital a Vitoria, esta idea quedó desechada. Finalmente, en diciembre de 1986, esta joya arquitectónica quedó bajo propiedad del Gobierno Vasco, mientras que la Diputación Foral de Bizkaia se hacía cargo de los jardines, siendo actualmente su uso de interés público.

En la puerta principal del palacio, encontramos los Leones de la entrada, en base al diseño de Manuel María de Smith Ibarra realizado alrededor de 1914. Estos leones labrados en piedra se sitúan sobre unos pilares cilíndricos de ladrillo visto, que se conforman de manera helicoidal. Estos pilares aparecen unidos al arco Tudor del ingreso a través de lienzos de ladrillo visto con remates almacenados. En su interior igualmente hay una reproducción del Discóbolo de Mirón, nuevamente diseño de Manuel María de Smith Ibarra de fecha similar al anterior.

Relacionado con el palacio también encontramos la reproducción de un torso y cuatro columnas clásicas, diseño de Manuel María de Smith Ibarra (alrededor de 1914), ubicadas en una rotonda situada muy cerca del Palacio Artaza. Se trata de unas piezas que fueron extraídas del palacio para ser depositadas en esta nueva ubicación. En relación a las columnas, debemos mencionar que anteriormente tuvieron la función de sustentar el entablamento de una pérgola, pero que debido a su profundo estado de deterioro, se propuso cambiarlas de emplazamiento. Se trata de unas columnas clásicas, con algunos referentes de la tipología jónica. En lo que respecta al torso, situado en la parte central de la rotonda, su tratamiento formal nos trae numerosos recuerdos, desde la Ménade Danzante del siglo IV a.C. de Escopas hasta las figuras situadas en el Gran Altar de Zeus y Atenea en Pérgamo; así como al Torso de Belvedere de Apolonio de Néstor; y las esculturas del frontón occidental del templo del Partenón, entre otras. Igualmente, podríamos generar una serie de relaciones más contemporáneos, ya que se presentan ciertas correlaciones físicas con el Gran guerrero, con pierna derecha (1900) de Antoine Bourdelle. No obstante, bajo un exhaustivo examen, el parecido más cercano se orienta hacia el estilo pergameneo en relación a la escultura del altar de Zeus en Pérgamo. Exactamente, se trataría de una copia de la figura de Menelao dentro del grupo Menelao que lleva a Patroclo, aunque ha habido otras interpretaciones, como Ayax llevando a Aquiles, de acuerdo a una obra original del barroco helenístico en la tradición pergamenea del Altar de Zeus, que data de finales del siglo III a.C.

Sin relación directa con el Palacio Artaza, pero vinculado con Manuel María de Smith Ibarra, su nieto y también arquitecto José María de Smith Solaun, diseña en 2006 una serie de diez atlantes (Fig. 6), que aparecen en uno de los edificios situado en el Boulevard Udondo. El arquitecto José María de Smith Solaun desde siempre ha mantenido un interés por el ámbito escultórico y prueba de ello es la materialización de este conjunto de atlantes, de hecho, la relación entre la escultura y la arquitectura es una vieja práctica combinatoria durante la historia del arte, por este motivo, para este arquitecto, resulta difícil asumir un edificio sin tener en cuenta la posibilidad de 
ubicar propuestas escultóricas.

La colocación de los atlantes responde a una dinámica de carácter intuitivo, ya que mientras se iba formalizando el diseño del edificio, el arquitecto comprobó la posibilidad de encajar una serie de esculturas, aspecto este que impulsó la creación de una serie de dibujos de figuras en cuclillas y cercanas a posturas sedentes. Como el porticado de las viviendas mantenía una potente volumetría visual, con una severa sensación de peso marcada por el efecto de la materia compacta que se había implantado, una solución válida y directamente estética fue acomodar una serie de esculturas que respondieran al perfil funcional y estético de los atlantes. Se buscó una solución artística y estética más que propiamente técnica dentro de este espacio intermedio, llegando a la conclusión de la necesidad de la colocación de unos telamones desnudos con cuerpos herculáneos.

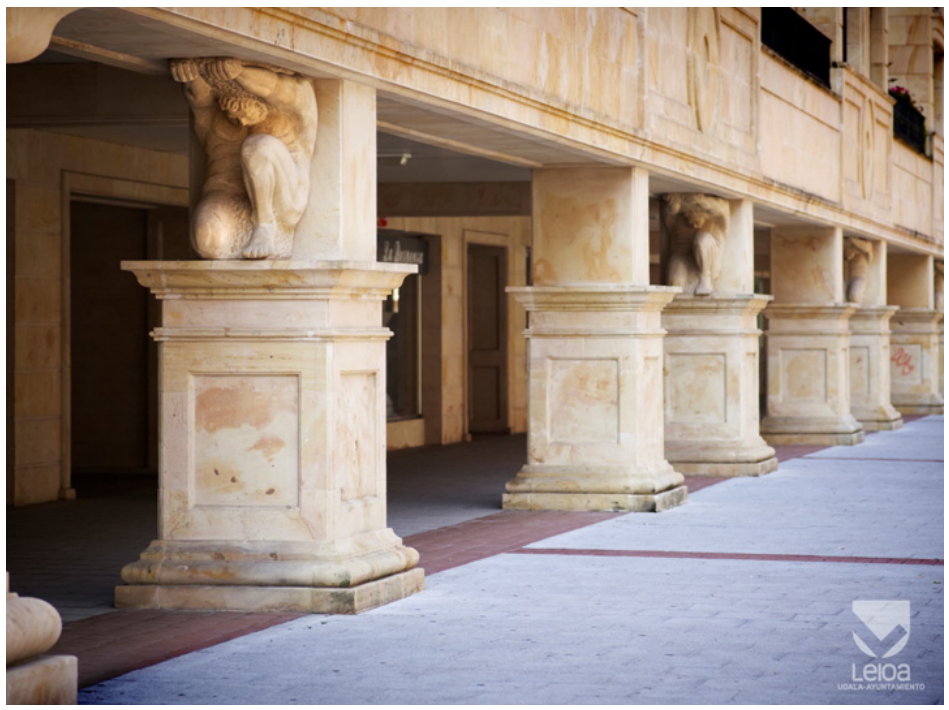

Figura 6. Diseño de José María de Smith Solaun. Serie de diez atlantes, 2006. Procedencia: Ayuntamiento de Leioa.

Por último hay toda una serie de propuestas que conllevan una mayor dificultad para insertarlas en grupos temáticos mayores, caso de Sin título de Rob Krier, las esculturas relacionadas con juegos infantiles de Diego Cruz, un cruceiro de autor anónimo, posiblemente realizado a mediados del siglo XX y el Obelisco, pieza situada entre la escultura y la arquitectura, diseñada por los arquitectos Iñaki Aurrekoetxea e Iñigo Viar a mediados de los años 90.

Por último fuera del ámbito público, es destacable la presencia de un nutrido conjunto escultórico en centros educativos privados, piezas situadas generalmente en lugares de ocio y esparcimiento, así como al aire libre dentro de estos edificios educativos, como Amistad (2001) de Javier Santurtun, Retrato del padre Claret (1978) de José Borlaf Rebollal y los monolitos de Bernat Vidal y Jon Martínez Zurinaga, entre otras. 


\section{Conclusiones}

Dentro del municipio vizcaíno de Leioa, el entramado de la escultura pública se ha convertido en una parte fundamental del paisaje y la concepción urbana, convirtiéndose su presencia en un reflejo de la evolución económica, social y urbana de esta población.

El importante número de piezas escultóricas esparcidas por toda la localidad, alrededor de unas treinta obras, favorece que el espectador se tope a diario con éstas, haciéndole partícipe de un patrimonio que recoge en muchos casos constantes históricos y culturales de su propio municipio. Este destacado conjunto de esculturas resulta muy interesante, ya que no estamos hablando de una localidad que haya mantenido un gran interés histórico-cultural dentro del ámbito vizcaíno, si evidentemente lo comparamos con la potencialidad cultural de otras poblaciones vecinas. Quizás, este aspecto ha podido ser uno de los resortes para promover una política municipal a favor de construir un paisaje urbano engarzado por piezas escultóricas, de ahí que uno de los referentes culturales de esta localidad sea actualmente su patrimonio escultórico público.

La ubicación de las distintas esculturas públicas por los diversos barrios de Leioa ha generado la sensación de una mayor recuperación espacial, a la vez que ha fomentado el proceso de humanización dentro del marco urbano. No obstante, las piezas de mayores dimensiones se han situado en espacios vinculados con las vías rodadas, especialmente la autovía Bilbao-Getxo y algunas de sus rotondas.

Entre las dos premisas prioritarias que ha impulsado el consistorio leioaztarra, la primera ha sido evidentemente la de embellecer los espacios urbanos y, en segundo lugar, mantener viva la memoria de personajes que sobresalieron por realizar una destacada labor social, intelectual y cultural a favor de este municipio. Por este motivo, las piezas ubicadas en este municipio responden a intervenciones técnicas, con el objetivo de acondicionar espacios urbanos, dentro de un plan de equipamiento urbano, siendo esta la tónica habitual en la configuración de la mayoría de los municipios españoles. Por este motivo, no se encuentran propuestas artísticas relacionadas prioritariamente con el sentido estético frente al marco constructivo, ya que siempre este segundo ámbito ha sido la plataforma para la realización de las distintas piezas, de hecho, la ejecución de las esculturas siempre se ha gestionado una vez que el espacio urbano estaba ya configurado, acomodándose el escultor a la distribución urbana.

Por último, debemos señalar que la financiación para la realización de estas esculturas generalmente son de procedencia institucional pública, destacando de manera especial el propio Ayuntamiento de Leioa y la Diputación Foral de Bizkaia, resultando de carácter más excepcional la aportación empresarial o la participación vecinal.

El interés que se ha venido mostrando desde décadas por parte de este consistorio en promover e impulsar una política que favoreciera la realización y distribución de esculturas públicas ha permitido que esta localidad cuente con un interesante repertorio plástico público, que ofrece al ciudadano un paisaje urbano y escultórico con un carácter histórico y simbólico, convirtiéndose algunos de sus lugares en 
emblemáticos por la significación de sus piezas, favoreciéndose un sentido de identidad con el propio espacio.

\section{Referencias}

Armajani, S. (2004). Public Art and the City. En Matzner, F. (ed.). Public Art: A Reader (66-71). Ostfildern-Ruit, Germany: Hatje Cantz.

Arrillaga, J.C. (2009). La escultura pública en las Comunidades Autónomas Vasca y Navarra como medio para la educación estética (1975-2000). Tesis doctoral defendida en 2009 en la Universidad del País Vasco.

Barandiarán, J. M. (2006). Mitología del pueblo vasco/Euskal Herriaren Mitologia. Lasarte-Oria: Etor-Ostoa.

Baroja, J. (1974). Algunos mitos españoles. Madrid: Ediciones del Centro.

Basañez, J. (1971). Lejona. Anteiglesia vizcaína. Bilbao: La Editorial Vizcaína.

Castañer López, X. (2002). Esculturas en espacios públicos de Vitoria-Gasteiz. Vitoria: Ayuntamiento de Vitoria-Gasteiz.

Gette, P-A. (2004). Notes on Art and the Public. En Matzner, F. (ed.). Public Art: A Reader (287-291). Ostfildern-Ruit, Germany: Hatje Cantz.

Maderuelo, J. (1994). Arte público. Huesca: Diputación de Huesca.

Maderuelo, J. (2001). Poéticas del lugar. En AA.VV. Poéticas del lugar. Arte público en España. Lanzarote: Fundación César Manrique.

López Asensio, A. (2001). Leioa a través de la historia. Leioa: Ayuntamiento de la Anteiglesia de Leioa.

Lozano Bartolozzi, M.M. (1989). Escultura pública y monumentos conmemorativos en Cáceres. Cáceres: Universidad de Cáceres.

Rossi, A. (1979). La arquitectura de la ciudad. Barcelona: Gustavo Gili.

Sánchez, E. (2007). Entre tornos, gubias y cinceles.... En AA.VV. Jesús Lizaso. Fuente de capacidad creativa (19-26) Bilbao: Vórtice Holding.

Senie, H.F. (1992). Contemporary Public Sculpture. Tradition, Transformation and Controversy. Oxford: Oxford University Press.

Terriza, G. (1994). La figura de la lamia en la literatura y las creencias populares del mundo antiguo. Memoria de Investigación. Madrid: UNED.

Zulaika, J. (2003). Un americano entre los vascos (5-16). Prólogo a Douglass, William A. Muerte en Murélaga. Irún: Alga Ensayo. 